\title{
OS LIVROS DIGITAIS DE FOTOGRAFIA DA COLEÇÃO FESTEJO MAIOR: NEXOS POSSÍVEIS ENTRE DESIGN, ETNOGRAFIA E ANTROPOLOGIA VISUAL
}

\author{
Cristiane Gusmão Nery, doutoranda \\ Universidade do Estado de Minas Gerais \\ nery.cris@gmail.com \\ Lucas Augusto Campos Magalhães \\ Universidade do Estado de Minas Gerais \\ lucas.acmagalhaes@gmail.com \\ Jairo José Drummond Câmara \\ Universidade do Estado de Minas Gerais \\ jairo.camara@uemg.br \\ Sebastiana Luiza Bragança Lana \\ Universidade do Estado de Minas Gerais \\ sebastiana.lana@gmail.com
}

Resumo: Este artigo versa sobre os nexos possíveis entre Design, Antropologia Visual e o método etnográfico aplicado no desenvolvimento de produtos culturais, mais especificamente, livros de fotografias. Para tanto será apresentado o processo de criação dos livros da Coleção Festejo Maior. O projeto de pesquisa e extensão Coleção Festejo Maior foi desenvolvido em 2015 e como resultado, foram produzidos e disponibilizados para toda a comunidade, via CD-ROM e Internet, seis livros digitais de fotografias de seis Guardas de Congado da região metropolitana de Belo Horizonte. O objetivo era, principalmente, utilizar o Livro de Fotografia como meio para preservar e divulgar a memória, e, consequentemente, o patrimônio material e imaterial de culturas tradicionais afro-brasileiras.

Palavras-chave: Antropologia Visual, Design, Livro de Fotografia, Patrimônio Cultural Imaterial, Congado.

\begin{abstract}
This paper discusses the possible links between Design, Visual Anthropology and ethnographic method applied in the development of cultural products, more specifically, photobooks. To do so will be analyzed the process of creating the books Coleção Festejo Maior. The Festejo Maior book collection was developed in 2015 and, as a result, six digital photobooks of six Brotherhood of Our Lady of the Rosary from the metropolitan region of Belo Horizonte were produced and made available to the entire community, via CD-ROM and Internet. The objective was mainly to use the Book of Photography as a means to preserve and
\end{abstract}


promote the memory and therefore the tangible and intangible heritage of traditional african-Brazilian cultures.

Keywords: Visual Anthropology, Design, Photobooks, Intangible Culture Heritage, Brotherhood of Our Lady of the Rosary.

\section{INTRODUÇÃO}

Este artigo versa sobre o desenvolvimento de produtos culturais, mais especificamente, sobre os livros de fotografias voltados para a cultural imaterial, por meio de uma reflexão acerca dos nexos possíveis entre Design, Etnografia e Antropologia Visual. Para tanto, será apresentado o processo de criação dos livros digitais da Coleção Festejo Maior ${ }^{1}$.

O projeto de pesquisa e extensão Coleção Festejo Maior foi desenvolvido em 2015 na Escola de Design / UEMG. Como resultado, foram produzidos e disponibilizados para toda a comunidade, via CD-ROM e Internet, seis livros digitais de fotografias de seis Guardas de Congado ou Reinado da região metropolitana de Belo Horizonte. São eles: 1 - Guarda de Moçambique de São Benedito de Prudente de Morais/MG 2 ; 2 - Guarda de Congo Estrela do Oriente do bairro Tupi de Belo Horizonte3; 3 - Guarda de Congo São Bartolomeu do bairro Concórdia de Belo Horizonte $; 4$ - Irmandade de Moçambique da Nova Gameleira de Belo Horizonte ; 5 Irmandade de Ibirité/MG ${ }^{6}$; 6- Banda de Congado Nossa Senhora do Rosário e Nossa Senhora da Guia de Conselheiro Lafaiete/MG ${ }^{7}$.

O Congado, também conhecido como Reinado, é uma religião de matriz africana e católica, sendo que os livros em pauta retratam suas festas para Nossa Senhora do Rosário ${ }^{8}$. A equipe de trabalho era constituída de uma professora (Cris Nery) que coordenava o projeto e dois alunos bolsistas sob sua orientação. Apesar de a equipe de trabalho ser pequena, eram muitos devotos e guardas envolvidos com o projeto. Um dos bolsistas (Lucas Magalhães), na época aluno do último ano do curso

\footnotetext{
${ }^{1}$ Os livros estão disponíveis na página da Escola de Design ou na plataforma ISSUU. Disponível em: http://www.ed.uemg.br/publicacoes Acesso em: 10 set. 2016.

Disponível em: https://issuu.com/crisnery/docs Acesso em: 10 set. 2016.

${ }^{2}$ Disponível em: https://issuu.com/crisnery/docs/01.guarda_de_mocambique_sao_benedit Acesso em: 10 set. 2016.

${ }^{3}$ Disponível em https://issuu.com/crisnery/docs/02.guarda_de_congo_estrela_do_orien Acesso em: 10 set. 2016.

${ }^{4}$ Disponível em: https://issuu.com/crisnery/docs/03.guardas_de_congo_e_mocambique_de Acesso em: 10 set. 2016.

${ }^{5}$ Disponível em: https://issuu.com/crisnery/docs/04.irmandade_de_mocambique_de_nossa Acesso em: 10 set. 2016.

${ }^{6}$ Disponível em: https://issuu.com/crisnery/docs/05.irmandade_de_nossa_senhora_do_ro Acesso em: 10 set. 2016.

${ }^{7}$ Disponível em https://issuu.com/crisnery/docs/06.banda_de_congado_nossa_senhora_d Acesso em: 10 set. 2016.

${ }^{8}$ Para saber mais sobre o Congado:

SOUZA, Marina de Mello e. Reis Negros no Brasil Escravista: história da festa de coroação de Rei Congo. Belo Horizonte: Editora UFMG, 2002.

PEREZ, Léa Freitas; MARTINS, Marcos da Costa; GOMES, Rafael Barros. Variações sobre o Reinado: um rosário de experiências em louvor a Maria. Porto Alegre: Medianiz, 2014.
} 
de design gráfico, já havia participado de projetos anteriores. Assim, devido à sua experiência e ao contato anterior com as guardas, ficou responsável pelas fotografias e pelo design gráfico. O outro bolsista era aluno do primeiro ano de Design de Produto e ficou responsável pela organização do material, pelos CDs, DVDs e redes sociais.

O objetivo da pesquisa era, principalmente, utilizar o Livro de Fotografia como meio para preservar e divulgar a memória, e, consequentemente, o patrimônio material e imaterial de culturas tradicionais afro-brasileiras. Para o desenvolvimento dos livros (pré-produção, produção e pós-produção), foram adotados diferentes métodos oriundos de diversos campos do saber: Fotografia Documental, Etnografia, Antropologia Visual, Design Editorial e Fotolivro.

\section{DESENVOLVIMENTO}

\subsection{Do livro de fotografia}

Fotografias podem ser apreciadas em diversos suportes e situações, desde álbuns de família a peças de publicidade, jornais, revistas, sites, blogs, exposições em grandes galerias e museus. Porém, há uma situação especial, que de alguma maneira aproxima o espectador da imagem retratada, que o toca, que o emociona, que o envolve: o livro de fotografia. A fotografia transmutada em página adquire qualidades latentes e as emite com máxima potência. Em um livro, a fotografia excede o limite da captação da imagem, ao se entregar a um processo de criação que abraça, principalmente, a edição das imagens e o projeto editorial. Nesse percurso, tem-se dois momentos imperativos que devem ser realizados primorosamente, de forma que a obra concluída possa expressar com toda força o que, porventura, se possa denominar de conceito, anseio ou narrativa. Seguindo mais além, por que não alcunhar o que se manifesta no volver dessas páginas de lirismo e poesia?

Fernandes Jr.e Entler (2014) afirmam que, no livro, as fotografias

[...] se articulam entre si e com outras linguagens para compor um pensamento mais elaborado. Ali se evidencia um processo de criação que se estende para muito além da captação da imagem. Com isso, as fotografias reivindicam outro tempo, outra profundidade do olhar, e se oferecem ao mundo como instrumento de crítica. [...] Tecnicamente, o livro é mero suporte para seu conteúdo; mas ele também é forma, desenho, objeto. É um dos primeiros artefatos a anunciar a era da reprodutibilidade técnica. Mas, assim como uma fotografia, ele se singulariza em nossas coleções como matéria carregada de memória, de afeto e de desejo. [...] A fotografia, enquanto repensa a si própria, tem ajudado a repensar o estatuto do livro. (EDITORA TEMPO D'IMAGEM, 2014.)

Segundo Lefèvre (2003) e Grigolin (2013), existem diferentes publicações que incorporam fotografias em seu miolo. Cinco tipos aqui nos interessam. O primeiro, livros que apresentam a obra de um fotógrafo, seu portfólio, que pode condensar um momento, um período ou a sua vida, lembrando também da própria linguagem fotográfica e da expressão do autor. O segundo, os catálogos de exposição, que são livros que acompanham exposições fotográficas e as têm como referência do seu conceito editorial. O terceiro, livros que incluem elementos textuais, nos quais a fotografia não se apresenta apenas como uma ilustração, mas se observa um processo 
em que tanto texto quanto imagem são protagonistas e se complementam; O quarto, Fotolivro, cuja premissa é criar uma narrativa onde o trabalho é coletivo e normalmente realizado pelo fotógrafo e pelo designer, que trabalham conjuntamente durante toda a criação do livro. O quinto, o Livro de Artista, é aquele em que um artista plástico é o responsável, de modo que o livro reflete suas preocupações e sua sensibilidade, fazendo com que o livro não seja apenas o suporte, mas a obra em si, o instrumento para a sua expressão artística individual.

Como principal característica da elaboração do conteúdo de um projeto editorial, o fotolivro traz imagens em sequência com ordens elaboradas a partir da narrativa que o fotógrafo tem como intenção apresentar. Todos os elementos - a paleta de cores, a coerência formal, o formato, o papel, a impressão - são escolhidos para fundamentá-lo enquanto objeto de arte. Até aqui, pode-se pensar que o projeto editorial de uma obra desse tipo pode ser desenvolvido como outro qualquer, por exemplo, em situações em que fotografias passam por galerias ou mostras antes de chegarem ao objeto livro. Nesse caso, o fotolivro é elaborado ao mesmo tempo em que é desenvolvido o projeto editorial, sendo ele o próprio objeto de arte.

O Trama, Grupo de Estudos localizado em São Paulo, é responsável pelos atuais debates em torno do tema. Tal grupo é filiado ao Estúdio Madalena ${ }^{9}$, coordenado por latã Canabrava, renomado estudioso e especialista em Fotolivros no Brasil, além de ser autor de alguns fotolivros que ganharam projeção ${ }^{10}$. O fotolivro é muitas vezes um trabalho coletivo, processo onde participam designer e editor concomitantemente ao fotógrafo, sobretudo quando se trata de definir a prerrogativa do livro. "Comentamos vários exemplos, entre os quais os fotolivros de outros convidados do evento do MIS, como 'Ausente' da fotógrafa Gordana Manic e 'Mulheres Centrais' e 'Tietê' do coletivo Garapa." 11 .

O fotolivro é um conjunto de imagens fotográficas pensadas, desde a sua concepção, para o formato livro, projeto em que fotógrafo, o designer e o editor trabalham juntos com papéis de igual peso na composição do discurso fotográfico e na tomada das decisões editoriais. Acima de tudo, para que se reconheça um legítimo fotolivro, é preciso que se garanta a relação interna das imagens, evitando que as partes tenham mais importância que o todo.

Essa premissa de designer, editor e fotógrafo trabalharem juntos desde o início, durante a organização do conteúdo editorial, garante que se encontre uma forma adequada à sequencia das imagens - opondo-se ao modelo adotado atualmente, no qual o projeto editorial só passa a ser desenvolvido após o conteúdo do livro estar totalmente definido, isto é, durante e após o desenvolvimento do projeto editorial.

\subsection{Dos nexos entre design, etnografia e antropologia visual}

Atualmente, a necessidade de se dar forma a um produto é, principalmente, uma questão muito mais semântica, comunicativa e ergonômica do que somente tecnológica. Nos cenários cada vez mais efêmeros e complexos, o designer deve ver o mundo e a cultura projetual mediante uma ótica mais alargada, não apenas voltada

\footnotetext{
${ }^{9}$ Disponível em: <http://estudiomadalena.com.br/ > Acesso em: 30 mai. 2016.

${ }^{10}$ Disponível em: <http://madalenacei.com.br/professor/iata-cannabrava/ > Acesso em: 30 mai. 2016.

${ }^{11}$ Disponível em: <http://tramafotolivros.tumblr.com/post/88408025528/trama-2-no-mis > Acesso em: 30 mai. 2016.

Disponível em: <http://estudiomadalena.com.br/encontro/ > Acesso em: 30 mai. 2016.
} 
para as questões do produto em si, mas de igual forma para a dinâmica que existe em seu entorno. Tal habilidade requer do profissional uma vivência transdisciplinar, voltada para o comportamento humano e para os valores de estima. (MORAES, 2011). Essas novas perspectivas exigem do designer outras posturas diante do problema ou projeto, uma vez que, na "contemporaneidade um dos grandes desafios do designer é comunicar e valorizar a identidade de produtos em um contexto global." (KRUCKEN; SAIKALY, 2010, p. 46).

Nesse processo, o resgate e a valorização da cultura local para um contexto globalizado, foram largamente utilizados, assim como os métodos oriundos da Antropologia. Isso foi possível porque a Antropologia é "um conjunto de teorias (nem sempre concordantes) e diferentes métodos e técnicas de pesquisa que buscam explicar, compreender ou interpretar as mais diversas práticas dos homens e mulheres da sociedade" e "muitas dessas teorias baseiam-se em pesquisas de campo, nas quais os antropólogos buscam conviver com as populações locais e aprender seus hábitos, valores, modos de vida, crenças, relações de parentesco e outras dimensões da vida social" (SANTOS, 2005, p. 19).

Bichard e Gheerawo (2011) apontam que a etnografia tem sido o modus operandi principal da Antropologia (social e cultural em oposição ao biológico) desde o "nascimento" da prática com permanência de Malinowski (1961) nas Ilhas Trobriand.

Assim, a resposta para a pergunta "O que é a Etnografia" está na participação no cotidiano das pessoas por um período prolongado de tempo; observando, ouvindo, pedindo e recolhendo tudo o que pode ser depois constituído como dado. Baskerville e Myers (2015) afirmam que o etnógrafo observa e participa, mas não procura ativamente mudar a situação. Explicam, porém, que últimos anos, um novo tipo de pesquisa etnográfica tem surgido - aquele que pode ser chamado de design ethnography.

Nesse novo tipo de pesquisa etnográfica, o pesquisador vai além da observação e, ativamente, se envolve com as pessoas no campo com o intuito de inovar ou de modificar aquela realidade, utilizando as ferramentas de design. Além disso, o pesquisador pode, a partir daquela realidade, perceber as oportunidades para diversos produtos, serviços e negócios. Nesse enfoque, Blomberg e Darrah (2015) argumentam que o olhar antropológico pode ser útil precisamente porque combina a atenção para detalhes da vida cotidiana, levando em consideração o meio em que tais detalhes fazem sentido.

Para tanto, é necessário refletir acerca da tradição textual da Antropologia. Normalmente, o produto final do trabalho de um antropólogo é apresentado em formato de texto, ou seja, em forma de publicações científicas. Seu trabalho, suas anotações, seus cadernos de campo e mesmo os registros imagéticos e sonoros são os dados a partir dos quais o antropólogo irá desenvolver seu pensamento, suas ideias, seus conceitos e suas teorias, de modo que tudo será apresentado textualmente.

Já a Antropologia Visual, um ramo da Antropologia, mantém sua relação com o texto, mas acrescenta a possibilidade de apresentar seus resultados de outras formas, propondo que texto e imagem tenham pesos iguais diante do registro do conhecimento humano.

Desse modo, observa-se a proposição de que é necessário pensar nas complementaridades heurísticas possíveis entre texto e imagem. Os antropólogos visuais iniciam seus trabalhos com a consciência de que seus resultados podem ser 
convertidos em forma de textos, ensaios fotográficos, CDs de músicas, registros sonoros, documentários, websites, acervos digitais e físicos, livros de fotografia, desenhos e uma série de outros produtos que terão de conter os aspectos culturais dos quais se originaram. Todas essas possibilidades de produtos culturais foram apresentadas durante o Encontro Internacional de Antropologia Visual, realizado de 03 a 08 de novembro de 2014 pelo LISA - Laboratório de Imagem e Som em Antropologia - e pelo GRAVI - Grupo de Antropologia Visual da USP - Universidade de São Paulo. Os processos de criação e a metodologia da Antropologia Visual contemplam como fazer a transposição dos dados colhidos em campo para os produtos culturais, o que pode ser um fator diferencial em um projeto de design.

Assim, vale ressaltar a abordagem de Dennison (2015) ao explicar que, embora muito tenha sido escrito sobre o potencial do cinema, da fotografia e da arte visual e, em uma extensão menor, da hipermídia para comunicar informações etnográficas, tem havido pouca discussão sobre o potencial para o projeto gráfico. Inspirando-se no trabalho do designer gráfico Buffalo Nickel, que foi contratado para acompanhar um texto etnográfico, Dennison explora algumas das possibilidades que o design gráfico oferece no campo da Antropologia.

Corroborando tal ideia, Caiuby Novaes, autora reconhecida no campo da antropologia visual, em seu artigo intitulado $\mathrm{O}$ uso da imagem na Antropologia, reitera que:

\begin{abstract}
Imagens, assim como os textos, são artefatos culturais. É nesse sentido que a produção e análise de registros fotográficos, fílmicos e videográficos podem permitir a reconstituição da história cultural de grupos sociais, bem como um melhor entendimento de processos de mudança social, do impacto de frentes econômicas e da dinâmica das relações interétnicas. Arquivos de imagens e imagens contemporâneas coletadas em pesquisa de campo podem e devem ser utlizados como fontes que conectam os dados à tradição oral e à memória dos grupos estudados. Assim, o uso da imagem acrescenta novas dimensões à interpretação da história cultural, permitindo aprofundar a compreensão do universo simbólico, que se exprime em sistemas de atitudes por meio dos quais grupos sociais se definem, constroem identidades e apreendem mentalidades (CAIUBY NOVAES, 2005, p. 110).
\end{abstract}

Essa afirmação permite reconhecer um dos nexos da Antropologia Visual com o design: ir à campo já com o intuito de transformar os dados em produtos específicos. As questões sobre o uso da imagem na Antropologia estão longe se se esgotar e, em razão disso, Samain (2012b, p.17) lança o convite para "deixar germinar novas ideias em torno da imagem, de todas as imagens".

O Design se aproxima da Antropologia de diversas maneiras. Isso pode ser observado tanto na utilização do trabalho de campo e da etnografia no desenvolvimento de um projeto, quanto no processo de se agregar valor a produtos, ambientes e peças gráficas ao se levar em conta os aspectos culturais regionais. Esse raciocínio remete a determinadas áreas imprescindíveis atualmente, tais como design social, design e artesanato, economia criativa, design e território. Em tais áreas já existem estudos significativos sobre essa aproximação. 
Partindo-se desse contexto, vale refletir acerca do desenvolvimento de produtos culturais, mais especificamente, livros de fotografias. Para tanto, será apresentado o processo de criação dos livros da Coleção Festejo Maior.

\subsection{Do processo de criação dos livros de fotografia da coleção festejo maior}

O desejo de fazer um livro para cada Guarda de Congado surgiu após a publicação em 2012 do livro "Um Olhar sobre o Congado" desenvolvido, também, como projeto de pesquisa e extensão na Escola de Design/UEMG. Na época, coletou-se um número expressivo de bibliografia sobre o Congado. Além disso, uma aproximação forte e significativa foi feita com algumas guardas, o que possibilitou a continuação dos registros fotográficos em 2013 e 2014. Durante esse período, foram produzidas não só fotografias, mas também registros em vídeo das festas. Todo esse material foi entregue para as guardas envolvidas nos formatos de CDs e DVDs. Esse retorno é de extrema importância em projetos dessa natureza.

Como o contato entre as guardas e os pesquisadores era constante, foi possível perceber o grande interesse que os devotos manifestavam nos registros fotográficos e audiovisuais. Consequentemente, surgiram novos convites, feitos pelos devotos, para registrar outras festas, o que gerou um vasto banco de dados composto desse material. Como esses registros iam sendo organizados em formatos de DVDs e CDs, 0 material foi sendo revisitado constantemente. Dessa forma, foram selecionadas as festas que tinham maior número de fotografias, com o propósito de se produzir um livro para cada uma delas. Como o custo da impressão inviabilizaria o projeto, decidiuse publicar os livros no formato digital em PDF e pleitear patrocínio para impressão posteriormente. Como já existia uma rede social em que parte das fotografias das festas era disponibilizada e o acesso pelos devotos já era muito grande (1109 seguidores), seria possível divulgar os livros de forma parecida.

Os livros foram desenvolvidos em 2015 em três fases: pré-produção, produção e pós- produção. A busca pelos nexos possíveis entre os métodos do design, da etnografia e da Antropologia Visual foi fundamental em todas elas.
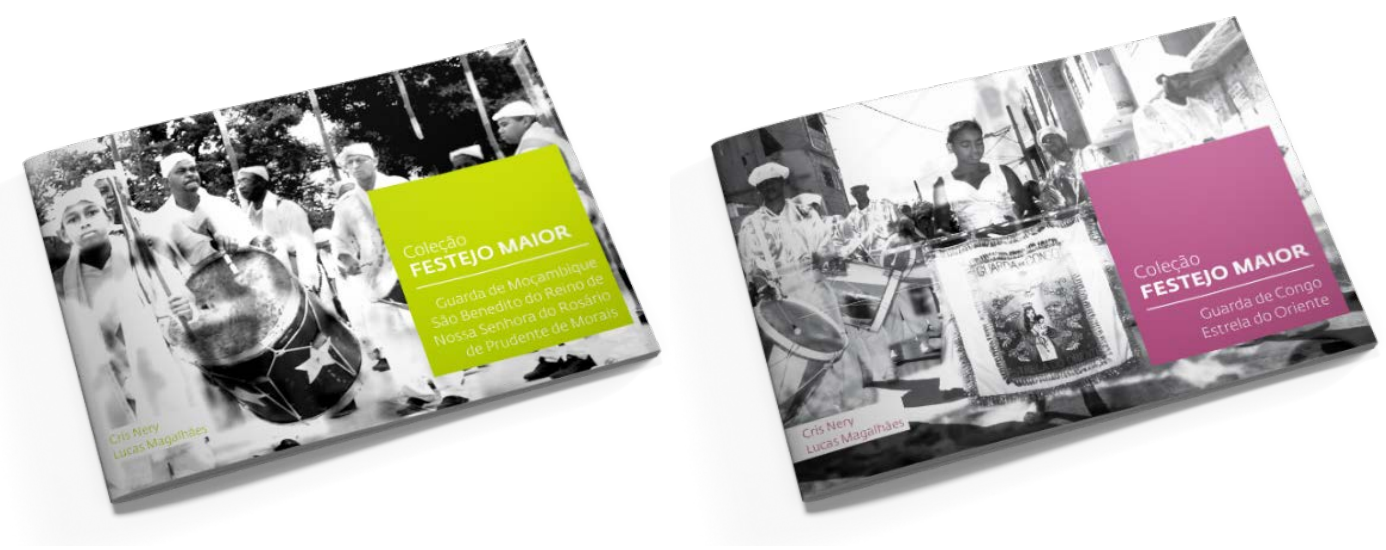

Figura 1 - Volumes 01 e 02 da Coleção Festejo Maior. Guarda de Moçambique São Benedito do Reino de Nossa Senhora do Rosário de Prudente de Morais e Guarda de Congo Estrela do Oriente. Disponível em: https://issuu.com/crisnery/docs/01.guarda_de_mocambique_sao_benedit e https://issuu.com/crisnery/docs/02.guarda_de_congo_estrela_do_orien Acesso em: 30 mai. 2016. Fonte: "Elaborado pelo autor, com base na pesquisa realizada". 
Durante a pré-produção, foram realizadas as seguintes etapas: análise do acervo de fotografias já existentes; agendamento das entrevistas e dos novos registros das festas; organograma do conteúdo dos livros, espelho dos livros.

$\mathrm{Na}$ fase de produção, as seguintes etapas foram seguidas: entrevistas; novos registros fotográficos das festas de congado; organização e seleção das imagens; transcrição das entrevistas, elaboração dos textos, tratamento e edição de todo o conteúdo dos livros. Criação de identidade visual para o projeto; conceituação e definição das peças gráficas a serem desenvolvidas (CD's, DVD's, editoriais, papelaria, marca, padronagens, cartazes de lançamento, material de divulgação etc.); geração de alternativas; decisão formal. Desenvolvimento de projeto editorial e diagramação. Reunião com as guardas para acompanhamento e aprovação do layout e da diagramação dos livros. Tratamento das imagens, arte final. Registro e ISBN dos livros; elaboração da ficha catalográfica e da ficha técnica; revisão final de texto. Produção dos mil exemplares de CD-ROM contendo os seis livros. Organização do lançamento.

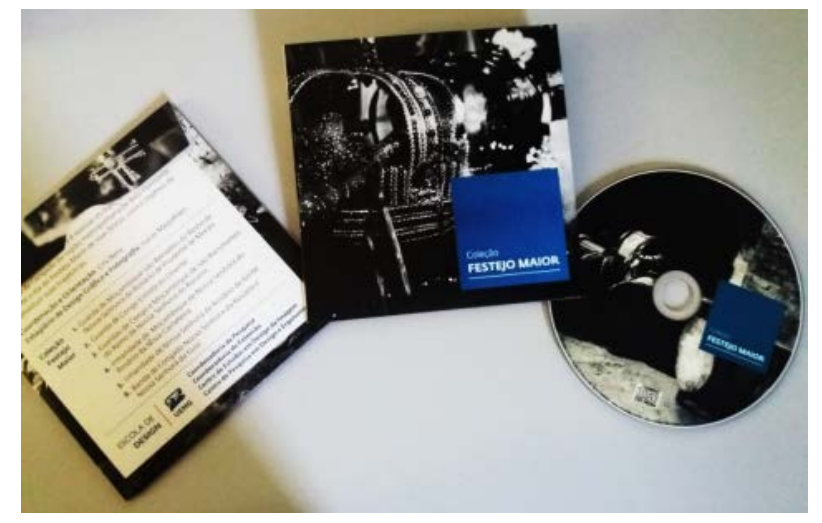

Figura 2 - CD-ROM contendo todos os livros da Coleção Festejo Maior. Fonte: "Elaborado pelo autor, com base na pesquisa realizada".

A fase de pós-produção contou com as seguintes etapas: publicação definitiva dos seis livros digitais de fotografia em formato PDF no site da Escola de Design/UEMG e na plataforma ISSUU; propagação e divulgação dos livros; lançamento. O lançamento dos livros foi realizado no dia 12 de setembro de 2015 na FUNARTE como evento integrante da Semana UEMG e da Virada Cultural da cidade ${ }^{12}$. Contou com a apresentação de duas Guardas de Congados e com a presença de mestres e capitães de Reinado. O CD-ROM foi distribuído gratuitamente para os presentes e disponibilizado para bibliotecas, pesquisadores, professores e alunos.

\footnotetext{
12 Reportagem sobre o lançamento no site da Escola de Design. Disponível em: http://www.ed.uemg.br/noticias/2015/09/semana-uemg-comeca-hoje Acesso em: 10 set. 2016. Reportagem sobre a virada cultural. Disponível em: http://www.soubh.com.br/eventos/virada-culturalfunarte/ Acesso em: 10 set. 2016.
} 

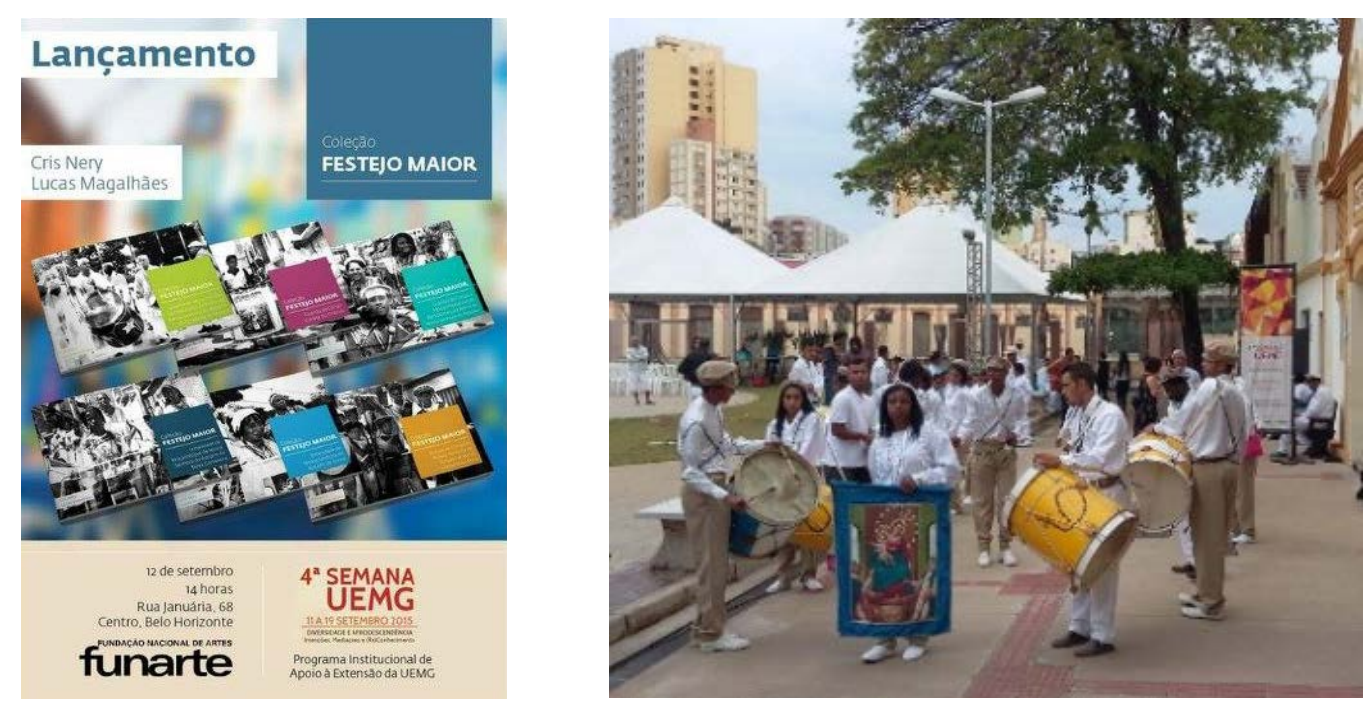

Figuras 03 e 04 - Cartaz do lançamento da Coleção Festejo Maior e apresentação da Guarda de Congo Estrela do Oriente durante o lançamento.

Fonte: "Elaborado pelo autor, com base na pesquisa realizada".

\section{CONCLUSÃO}

Ao analisar o processo de desenvolvimento dos livros da Coleção Festejo Maior, percebe-se que os métodos oriundos do Design, da Etnografia e da Antropologia Visual podem ser aplicados desde o início do desenvolvimento de produtos culturais, mais especificamente, de livros de fotografias que levantam a possibilidade de salvaguardar memórias e culturas imateriais. Neste artigo, defendeu-se a ideia de que tanto o formato impresso quanto o digital são importantes, de modo que um não substitui o outro, uma vez que se complementam. Desse modo, um livro que possui as duas versões aumenta o poder de propagação de seu conteúdo. No caso dos livros digitais de fotografia, a disponibilização pela internet para acesso remoto torna acessível a todos os interessados o conhecimento de objetos, fotografias e documentos, que só seriam possíveis de se conhecer por meio de uma visita presencial na sede das guardas. Os próprios devotos compartilham os livros em suas redes sociais particulares e, também, nas páginas das Guardas de Congado.

Morais (2010, p.35) cita a obra Heranças do Tempo, tradições afro-brasileiras em Belo Horizonte para ressaltar que o maior mérito de um inventário,

[...] além da investigação documental, é recuperar a autoestima dos grupos detentores de conhecimentos tradicionais que habitam em Belo Horizonte, resgatar seus saberes e fazeres, promover seu patrimônio histórico e cultural, através de sua memória coletiva (BELO HORIZONTE, 2006, p.8).

Dessa forma, essa reflexão acerca dos nexos possíveis entre Design, Etnografia e Antropologia Visual levanta discussões interessantes pelas possibilidades de promover o desenvolvimento de livros de fotografia pelo viés de uma perspectiva transdisciplinar, causando, desse modo, um impacto pela ação social transformadora. 


\section{REFERÊNCIAS}

BASKERVILLE R. L.; Myers M. D. Design ethnography in information systems. In: Info Systems J, 25, 23-46, 2015.

BICHARD, Jo-Anne; GHEERAWO, Rama. The ethnography in design. In: Design Anthropology: object culture in 21st century. Springer Vienna, 2011. p. 45-55.

BLOMBERG, Jeanette; DARRAH, Chuck. An Anthropology of Services: Toward a Practive Approach to Designing Services. Synthesis Lectures on Human-Centered Informatics, Morgan \& Claypool Publisher, n. 1, v. 8, February 2015.

CAIUBY NOVAES, S. O uso da imagem na Antropologia. SAMAIN, Etienne (Org.). 0 fotográfico. 2 Ed. São Paulo: Editora Hucitec; Editora Senac, 2005. p. 107-113.

DENNISON, Jean. Situating Graphic Anthropology. Visual Anthropology, v. 28, n. 1, p. 88-108, 2015.

ENCONTRO INTERNACIONAL DE ANTROPOLOGIA VISUAL. Disponível em: <http://eiav2014.blogspot.com.br/p/mesas-redondas.html>. Acesso em 30 mai. 2016. ENTLER, Ronaldo; JR. FERNANDES, Rubens. Tudo no mundo existe para terminar num livro de fotografia. In: Editora Tempo D'Imagem, 2014. Disponível em:

<https://www.facebook.com/editoratempodimagem/posts/836596233036239:0>. Acesso em 30 mai. 2016.

ESTÚDIO MADALENA. Disponível em: <http://estudiomadalena.com.br/>. Acesso em 30 mai. 2016.

GRIGOLIN, Fernanda. Livro de fotografia como livro de artista. Experiências de artistas: aproximações entre a fotografia e o livro. São José dos Campos: Publicações lara, 2013.

IATÃ CANABRAVA. Disponível em: <http://madalenacei.com.br/professor/iatacannabrava/>. Acesso em: 30 mai. 2016.

LEFRÈVE, Beatriz Vampre. Livros de Fotografia: história, conceito e leitura. 2003. 293 p. Dissertação (Mestrado em Multimeios) - Instituto de Artes, Universidade Estadual de Campinas.

MORAES, Dijon de. Metaprojeto como modelo projetual. In: MORAES, Dijon de; DIAS, Regina Álvares; BOM CONSELHO, Rosemary (Org.). Método. 1ed. Barbacena:

Ed/UEMG, 2011, v. 1, p. 35-51.

MORAIS, M. R. Ações do poder público e a prática da umbanda, candomblé e congado: Reflexões sobre a construção de patrimônios culturais. Latitude, Maceió, v.4, n.2, pp. 25-42, 2010. Disponível em: <http://www.seer.ufal.br/index.php/latitude/article/view/839/541>. Acesso em: 30 mai. 2016.

PEREZ, Léa Freitas; MARTINS, Marcos da Costa; GOMES, Rafael Barros. Variações sobre o Reinado: um rosário de experiências em louvor a Maria. Porto Alegre: Medianiz, 2014. 
SAIKALY, F.; KRUCKEN, L. Design de plataformas para valorizar identidades e produtos locais. In: Moraes, D.; Krucken, L.; Reyes, p. (Org.). Design e Identidade. 1 ed. Barbacena: Ed/UEMG, 2010, v. 1, p. 35-48.

SAMAIN, Etienne. As imagens não são bolas de sinuca. In: SAMAIN, Etienne (org.). Como pensam as imagens. Campinas, SP: Editora da Unicamp, 2012a. P. $21-36$.

SAMAIN, Etienne. Apresentação. In: SAMAIN, Etienne (org.). Como pensam as imagens. Campinas, SP: Editora da Unicamp, 2012b. P. 13 - 18.

SANTOS, Rafael José dos. Antropologia para quem não vai ser antropólogo. Porto Alegre: Tomo Editorial, 2005.

SEMINÁRIO PENSAMENTO E REFLEXÃO. Disponível na internet em:

<http://estudiomadalena.com.br/encontro/> Acesso em 30 mai. 2016.

SOUZA, Marina de Mello e. Reis Negros no Brasil Escravista: história da festa de coroação de Rei Congo. Belo Horizonte: Editora UFMG, 2002.

TRAMA FOTOLIVROS EM DISCUSSÃO. Disponível na internet em:

$<$ http://tramafotolivros.tumblr.com/post/88408025528/trama-2-no-mis>. Acesso em 30 mai. 2016. 